\title{
Diversity Management and Its Impact on HRM Practices: Evidence from Kuwaiti Companies
}

\author{
Oualid ABIDI ${ }^{*}$, Halil ZAIM ${ }^{* *}$, Dina YOUSSEF ${ }^{* * *}$, Houshang HABIBNIYA ${ }^{* * * *}$, \\ Alper BARAN ${ }^{* * * *}$
}

Received: October 19, 2017 Revised: November 26, 2017 Accepted: December 3, 2017

\begin{abstract}
The purpose of this paper is to analyze the Diversity Management implementation in Kuwaiti context and try to reveal its effects on human resource management practices. Data was collected through questionnaires from a variety of companies in the service sector in Kuwait. Convenient sampling method is applied. Among the questionnaires distributed 354 useful ones from 87 different companies were considered. An exploratory factor analysis (EFA) with varimax rotation is used to determine the underlying dimensions of HRM and DM. Furthermore, a regression analysis is used to measure the effects of diversity management on HRM.

The major findings of this study are as follows: first, there is a positive significant relationship between Diversity Management policies and Human Resources Management practices. The "ability to manage people from different backgrounds" have the most significant effect on HRM practices, followed by "Ability to work in harmony with people from different cultures" component, then "Avoidance of discrimination" component.
\end{abstract}

Keywords Diversity management, Human Resources management, Service Sector, Labor Market, Kuwaitization

JEL categories: M14, J24

UDC: 005.95(536.8)

DOI: https://doi.org/10.17015/ejbe.2017.020.05

\footnotetext{
* Associate Professor, American University of the Middle East, E-mail: Oualid.Abidi@aum.edu.kw ${ }^{* *}$ Corresponding author, Professor, American University of the Middle East, E-mail: Halil.Zaim@aum.edu.kw ${ }^{* * *}$ Assistant Professor, American University of the Middle East, E-mail: Dina.youssef@aum.edu.kw ${ }_{* * * * *}^{* *}$ Assistant Professor, American University of the Middle East, E-mail: Houshang.Habibniya@aum.edu.kw ${ }^{* * * * *}$ Independent Researcher. E-mail: alper.baran@gmail.com
} 


\section{Introduction}

Diversity management has attracted great attention of academics, practitioners and organizational researchers over the last few decades. The changing demographic composition of the workforce, the increasing social sensitivity to ethical concerns, and the overall consequences of globalization are compelling more and more organizations to deal with diversity management (DM) (Ravazzani, 2016).

Diversity and DM have several definitions. According to Kandola and Fullerton (1998) diversity means visible and non-visible differences of people such as sex, age, race, background, disability, personality and work style. Accordingly, DM starts with accepting these differences and aims to harness them to create a productive environment where everybody feels valued, their talents are being fully utilized and in which organizational goals are met (Kandola \& Fullerton, 1998).

Early studies in DM focused on affirmative action plans and improving equal employment opportunities of marginalized groups such as women, racial or ethnic minorities, disabled individuals and other designated groups as well as visible minorities. It is also important to note that early research in DM usually reflected national perspectives mainly originated from a limited number of countries (Klarsfeld, et al., 2016).

The need for DM for all multi-national companies increased given several factors including: the intensifying "war for talent", the changing nature of production, the increasing need for creativity and continuous innovation and the accelerating labor mobility (Friday \& Friday, 2003). Accordingly, in time, both content and coverage of DM progressed and managing diversities effectively became a strategic issue for organizations to gain sustainable competitive advantage in today's competitive global business environment (Bendl, Fleischmann, \& Walenta, 2008).

However, in comparison to Western countries, Asia (India and China) and Far East Region (Korea, Malaysia, Japan etc), Middle East, GCC region and Kuwait in particular has attracted less attention in DM literature (Jamali, Abdallah \& Hmaidan, 2010; Yaghi \& Yaghi, 2013). However, with an increasing number of multi-nationals investing in Kuwait particularly in service sector, more than $80 \%$ of its labor force is composed of expatriates from several different countries, Kuwait is obviously a special case for DM (Kuwait Central Statistical Bureau, 2015).

Hence, the main purpose of this study is to analyze the DM implementation in Kuwaiti context and try to reveal the effects of DM on human resource management. We proposed that DM is positively related with HRM, and try to prove this relationship through a field study based on data collected from companies in service sector in Kuwait.

Accordingly, the research model is composed of human resource management as a dependent variable, and diversity management practices as independent variables. 
Diversity management practices component is measured by three dimensions; ability to manage people from different backgrounds, ability to work in harmony with people from different cultures, and avoidance of discrimination

\section{Literature review}

\subsection{Diversity Management}

Diversity encompasses elements that go beyond gender, age, ethnicity, family status, and any other apparent identity reference. Subtle dimensions such as education, ideas and experience should be considered (Benschop, 2001). Therefore, several authors have suggested comprehensive frameworks to grasp diversity construct. For instance, Ardakani et al.(2016) posit that diversity is composed of four layers:

$>$ Personality.

$>$ Internal dimensions: Race, age, gender, sexual orientation, physical ability and ethnicity.

Dxternal dimensions: Geographic location, recreational habits, personal habits, income, religion, educational background, work experience, marital status, parental status and appearance.

$>$ Organizational dimensions: Management status, work content/field, union affiliation, seniority, functional level/classification, division/department/unit/ group, and work location.

There is limited evidence, indeed, on how diversity and inclusion issues are managed in emerging economies (Donnelly, 2015). Most studies investigating diversity management were conducted in Western countries using qualitative research protocols. Few of them have considered how diversity management, as part of strategic HRM has been applied in a less developed country, across different ownership forms - domestic vs multinational firms (Cooke \& Saini, 2010).

Several studies have pointed out to divergent HRM rhetoric from the real implementation of diversity and inclusion management strategies along the dimensions of age, gender and intra-and-international variations (Donnelly, 2015). Most of employees belonging to ethnic minorities were not aware of the existence of a formal commitment in their companies to promote diversity. The initiatives launched in those companies did not change the situation of minority members (Louvrier, 2014).

Diversity change initiatives can neglect the work group level, as organizations fail in establishing a positive climate to enhance the agreement that demographic shifts are favorable (Kossek, Markel \& McHugh, 2003).

Diversity Management affects six HRM areas: linking strategy to diversity, recruitment for diversity, selection for diversity, training and development of 
diverse staff, monitoring DEM effectiveness, and providing work-life flexibility (Konrad, Yang \& Maurer, 2016).

Overall, a plethora of diversity management approaches has been presented in previous studies. Most commonly, companies around the world are creating diversity charters to reinforce their engagement to support diversity (Louvrier, 2014). While diversity management is explicitly mentioned as policies, some other organizations simply state diversity management as part of HRM policy. Having formal diversity management policy statement does not necessarily guarantee effective implementation in practice. Likewise, lacking those formal rules does not imply that the organization is not managing diversity issues (Cooke \& Saini, 2010).

Cooke and Saini (2010) identified five categories of organizations, based on the type and extent of their diversity management approach:

$>$ Strategic diversity management: This is the most advanced approach to Diversity management as it is meant to enhance employees' performance and productivity through initiatives such as spreading cultural awareness, work-life balance, flex-time and encouraging the expression of diverse ideas.

$>$ Social justice approach: Stresses on corporate social responsibility and goes beyond the application of legal statements to regulate the behavior in the workplace (i.e., involvement of employees' family, well-being programs, maternity policy, maintenance of high standards of professionalism at work, etc.)

$>$ Affirmative action plans: Focus on gender equality and ethnic/religious equality by establishing manpower gender or ethnicity ratio.

$>$ Legal compliance: compliance with equal opportunity as per the legal requirements.

$>$ Ad hoc approach: Absence of formal diversity management policies. Diversity management issues are dealt with as they surface by line managers.

The latter increases the employment of workers with disabilities or belonging to visible minorities and enhances organizational financial performance. This reflects the core assumption advocated by strategic human resource management theory that claims a strong linkage between HRM practices and firm's strategy.

Nonetheless, the adoption of a specific diversity management practice varies according to the age, sector, nationality, and form of ownership (public vs private; domestic vs multinational) of the organization. Eventually, as Cooke and Saini (2010) explained, the nature of diversity management initiatives depends also on the attitude and the background of the Chief Executive Officer. In the same vein, knowledge intensive multinationals are more expected to undertake more proactive diversity and inclusion management in order to support their competitive advantage (Donnelly, 2015). 


\subsection{Diversity Management and Human Resource Management}

The outcomes of diversity management have been widely discussed in literature. Diversity management is likely to increase the representativeness of minority groups in workplaces. For example, minority opportunity-based diversity and equality management practices have a positive relationship with management team racial diversity in American companies, especially for African Americans and Asians. Minority opportunity-based diversity and equality management practices include "racial minority mentoring programs, racial minority network groups, internships for racial minorities, and career tracks for racial minorities with high potential as future managers." (Richard, Roh \& Pieper, 2013).

The same study proved the existence of another positive relationship between manager accountability -"providing managers with incentive pay when they meet organizational diversity goals and evaluating managers on diversity-related tasks or outcomes" - and minority representation in managerial positions. Those relationships tend to be stronger as the size of the company is smaller (Richard, et al., 2013).

Celebioglu (2017) also indicated in his study that the problem of gender inequality is dominant in the labor markets in Turkey, arguing that the problem has many dimensions including social, cultural, and economic dimensions. The study showed that several factors affect women employment including the level of socioeconomic development, gender equities, household size and wage gap (Celebioglu, 2017).

On the organizational level, diversity management is seen as a valuable HRM function that yields higher organizational performance and competitiveness (Cooke \& Saini, 2010). The multiplication of work-life balance programs supports positive effects of non-management gender diversity on productivity in organizations. On the contrary, with a poor portfolio of work-life balance programs, management gender diversity creates negative influence on the financial performance of the organization. As such, the promotion of work-family balance programs is likely to assure employees about employer's intentions about gender diversity, which can increase the potential of diversity in enhancing performance (Ali, Metz \& Kulik, 2015).

The same findings have been supported in another study that demonstrated a strong relationship between diversity management and organizational citizenship behavior (Jie, D’Netto \& Jiong, 2010). In this study, diversity management proved to be effective in creating an inclusive organizational culture that stimulates affective commitment and organizational citizenship behavior for both, native and non-native Dutch central government employees. This suggests that no variances exist in regards to the extent majority and minority socio-demographic groups react to diversity management programs. Hitherto, all groups would respond favorably if an inclusive work environment is established in the organizations 
(Ashikali \& Groeneveld, 2015). Another research proved that employees' perceptions of fairness of HRM practices has a positive effect on their organizational commitment (Hung et al., 2004).

Benschop (2001) argues that diversity shapes HRM practices, which engenders four types of outcomes: cognitive, affective, communicative and symbolic. Cognitive effects refer to the ability of the group to process information, react to stimuli and make decisions based on it. Affective effects stand for the attitude of workers towards their work, their colleagues and the organization. Communicative effects pertain to the fluidity and frequency of communication within and outside the group. Symbolic effects deal with the positive image that diverse group carry with internal and external stakeholders (Benschop, 2001).

Another result that corroborates to the importance of diversity management as a cardinal action in the success of any organization is its effect on human resource productivity through the mediating effect of perceptional variables (perceived attractiveness, perceived organizational justice and perceived social identity). Thereupon, human resource productivity is assessed through job satisfaction, turnover intention, organizational citizenship behavior, and job involvement (Ardakani, et al., 2016).

\subsection{Labor market in Kuwait}

Although the study of Arab cases was obviously disregarded in textbooks of "management", "HRM" and "international business", there is a recently increasing interest in the HRM systems in the Middle East (lles, Almhedie \& Baruch, 2012). With respect to labor market in Kuwait, the Labor Force Survey conducted by the Central Statistical Bureau (2015) showed an increasingly high diverse labor market in terms of nationality, gender, age, marital status, and educational level.

However, the Arabian Gulf countries have recently established localization efforts (named Kuwaitization in Kuwait), by setting quotas of a minimum ratio of local employees to expatriate employees to be hired, in addition to other policies, for the purpose of encouraging locals to enter the workforce, especially in the private sector (Goby, Nickerson \& David, 2015). Nevertheless, many studies indicated that fair human resources management and diversity management practices is considered as a tool for the success of the quota system, which, in turn, has positive effects on organizations (Lamba \& Choudhary, 2013; Naz, Aftab \& Awais, 2016; Forstenlechner, Lettice \& Özbilgin, 2012; Goby, et al., 2015).

\subsection{The HRM function in Kuwait}

The HRM function has developed in Kuwait following the change in the nature of the society. This evolution in the view point was addressed by Ali and Al-Kazemi (2006). In the early years, the HRM functions were not addressed adequately, till 1950s, when the oil production increased, development programs have been established, several infrastructure construction projects were initiated, and the 
number of expatriates significantly increased. After the unexpected increase in the prices of oil in 1973, the government started many economic development programs and established many state organizations in different sectors. This altered the point in the view of the HRM functions from being viewed as 'personnel management', which is only concerned with keeping records of clerical activities and advertising to job vacancies, to gradually considering HRM as an essential function. Accordingly, and as a result of the significant increase in number of labor force and in number of multinational corporations, both governmental and private organizations realized the importance of HRM and became more interested in its roles and functions. Hence, the increasing competition in the region, the increasing number of university graduates, and the privatization of state-controlled organizations force both government and business organizations to work on improving their efficiency and effectiveness, which, in turn, emphasizes the essential role of HRM (Ali \& Al-Kazemi, 2006).

\section{Research Objectives and Methodology}

As this study attempts to prove the existence of a positive impact of diversity management practices on HRM in Kuwaiti organizations, an empirical model was developed using data collected through questionnaires.

DM is captured through the organizational policies and programs that promote diversity in the workplace especially those dealing with the representation of minorities and women and the development of a sense of awareness of diversity issues. It is also reflected through management commitment and inclusive working approach (Ashikali \& Groeneveld, 2015).

HRM is a comprehensive term that could comprise several dimensions. Therefore, this study needs to include a relevant model to assess how HRM can evolve in response to enhanced DM in the organization. The framework suggested by Pfeffer (1998) is adopted in this study as a reference as it inspired a large part of previous studies on HRM practices (Marchington \& Grugulis, 2000). This model recognizes seven dimensions that mark any system conveying benefits through people, namely:

$>$ Employment security

$>$ Selective hiring

$>$ Self-managed teams and decentralization

$>$ Comparatively high compensation contingent on organizational performance

$>$ Extensive training

$>$ Reduced status differences

$>$ Extensive information sharing inside the organization

\subsection{Hypotheses and the Model}

As mentioned before it is assumed that there is a positive linear correlation between DM components and HRM practices. Hence, the hypotheses are: 
H1: HRM practices will be positively influenced if avoidance of discrimination is enhanced.

H2: HRM practices will be positively influenced if the ability to manage people from different backgrounds is enhanced.

H3: HRM practices will be positively influenced if the ability to work in harmony with people from different cultures is enhanced.

The research model is shown in the following figure:

Independent Variables

Dependent Variable

Diversity management Practices

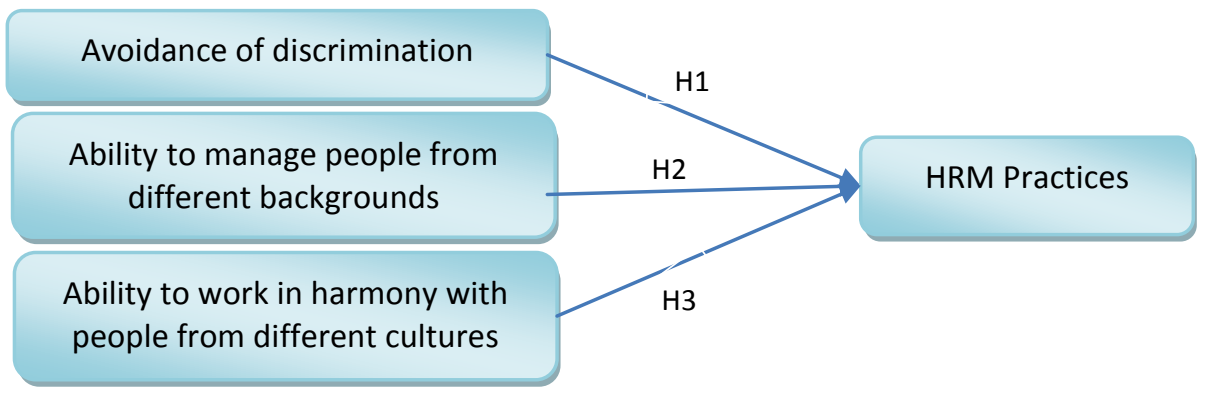

Figure 1. Research Model

\subsection{Survey Instrument}

The Survey instrument is a self-administered questionnaire and is composed of 29 questions. While six of those questions are demographic, two of them are reverse (control) questions. Apart from demographic questions, the questionnaire is composed of 2 main components: Human Resource Management (HRM) with 11 questions and Diversity Management (DM) with 12 questions. HRM component is adopted from Zaim (2016) which was originally derived from Pfeffer (1998). DM component is adopted from the research of Ashikali and Groeneveld (2015). Those researchers analyzed DM in two dimensions: Ability to manage people from different backgrounds and inclusive culture (Ability to work in harmony with people from different cultures). This study includes one more dimension, i.e. avoidance of discrimination based on gender, age, cultural background and education level. It is mainly because this dimension is considered by the authors as an essential part DM in Kuwaiti context due to the diversification of the labor force in terms of gender, cultural background, age and education level as mentioned earlier.

Each item is rated on a five-point Likert Scale anchored at the numeral 1 with the verbal statement "strongly disagree" and at the numeral 5 with the verbal statement "strongly agree". 


\subsection{Data Collection}

Data was collected from a variety of companies in service sector in Kuwait. Convenient sampling method was applied. The survey was conducted in fall 2016. The questionnaires were distributed to people who are able and willing to represent their companies and easy to access with the permission of the related companies. Data was collected through face to face or via electronic tools such as Survey Monkey and Google Survey Form. Approximately 100 companies operating in Kuwait in service sector and 500 employees were targeted. Among the questionnaires distributed 444 useful ones from 87 different companies were returned. On the other hand, 90 respondents did not want to answer demographic questions. That is why, for analysis of demographic characteristics of this survey, only 354 respondents were considered. Of these respondents, 57 per cent were males (of which 73 per cent were local Kuwaiti nationals and 27 per cent were expatriates), whereas 43 per cent were females (of which 85 per cent were local Kuwaiti nationals and 15 per cent were expatriates). Almost 78 per cent of the male respondents earned a university bachelor degree of which 42.6 per cent held an entry level and 21 per cent middle level of employment positions in both public and private Kuwaiti sectors.

\section{Data Analysis and Findings}

The data analysis was conducted in two steps; the first step is performing an exploratory factor analysis (EFA) with varimax rotation to determine the underlying dimensions of HRM and DM. The second step is conducting a regression analysis to measure the effects of diversity management on HRM.

\subsection{Exploratory Factor Analysis (EFA)}

In The EFA, 2 control items (reverse questions) were eliminated and 27 items were analyzed. These 27 items were yielded in 4 factors with Eigen values greater than 1 , which is convenient with our model. HRM questions appeared to be united in one factor. DM on the other hand yielded in three different factors. These are avoidance of discrimination, ability to manage people from different backgrounds and ability to work in harmony with people from different cultures. The factor loadings are shown in Table 1.

\subsection{Regression Analysis}

In order to test these hypotheses a multivariable regression analysis is performed using "Ordinary Least Squares Estimates" technique. We assumed that there is a positive linear correlation between DM components and HRM practices based on the existing literature mentioned earlier. The first step is assessing the significance of the model using ANOVA (F) Test that shows the combined effects of all the independent variables in the regression model. In order to consider the model to be significant, the general acceptance is that the significance level should be equal 
Oualid ABIDI, Halil ZAIM, Dina YOUSSEF, Houshang HABIBNIYA \& Alper BARAN

or less than \%5. As shown in Table 2, the model is significant. The results of the correlation analysis are also shown in table 4.

\section{Table 1. Exploratory Factor Analysis}

\begin{tabular}{cccc}
\hline HRM & $\begin{array}{c}\text { Avoidance of } \\
\text { discrimination }\end{array}$ & $\begin{array}{c}\text { Ability to manage people } \\
\text { from different backgrounds }\end{array}$ & $\begin{array}{c}\text { Ability to work in harmony with } \\
\text { people from different cultures }\end{array}$ \\
\hline 0.77 & -0.022 & 0.181 & 0.194 \\
0.73 & 0.317 & 0.138 & 0.084 \\
0.713 & 0.278 & -0.033 & 0.218 \\
0.691 & 0.038 & 0.252 & 0.168 \\
0.682 & 0.262 & -0.065 & 0.252 \\
0.681 & 0.158 & 0.23 & 0.044 \\
0.625 & -0.003 & 0.206 & 0.323 \\
0.623 & 0.016 & 0.38 & -0.23 \\
0.587 & -0.079 & 0.472 & 0.088 \\
0.548 & 0.134 & 0.437 & 0.119 \\
0.152 & 0.837 & 0.064 & 0.021 \\
0.174 & 0.791 & 0.236 & 0.126 \\
0.077 & 0.767 & 0.247 & 0.011 \\
0.072 & 0.665 & 0.015 & 0.245 \\
0.288 & 0.16 & 0.704 & 0.149 \\
0.293 & 0.182 & 0.677 & 0.173 \\
0.091 & 0.191 & 0.629 & 0.515 \\
0.134 & 0.283 & 0.618 & 0.424 \\
0.157 & 0.067 & 0.148 & 0.803 \\
0.166 & 0.234 & 0.427 & 0.625 \\
0.288 & 0.096 & 0.14 & 0.49 \\
\hline
\end{tabular}

Table 2. ANOVA Test

\begin{tabular}{lllllll}
\hline Model & & Sum of Squares & $\mathrm{df}$ & Mean Square & $\mathrm{F}$ & Sig. \\
\hline 1 & Regression & 126.781 & 3 & 42.26 & 88.157 & $0,000 \mathrm{~b}$ \\
& Residual & 208.529 & 435 & 0.479 & & \\
& Total & 335.31 & 438 & & & \\
\hline
\end{tabular}

a Dependent Variable: HRM

b Predictors: (Constant), DMyeni3, DMyeni, DMyeni2

The result of ANOVA test indicates that the model is significant, relaying a positive relationship between DM and HRM. This result is obviously consistent with the existing literature. For example, McMahan et al. (1998) and Baird and Meshoulam (1998) revealed the relationship between DM and HRM from a strategic point of view.

Furthermore, the adjusted $R^{2}$ (coefficient of multiple determination) is 0.374 which means almost $40 \%$ of dependent variable -HRM- can be explained by DM policies. Obviously there are many other factors behind HRM practices such as leadership, organizational, cultural and technological factors. However, almost $40 \%$ indicates a significant correlation between DM policies and HRM. 
The next step is to analyze the effects of DM components on HRM practices using "t-test" partial regression coefficients. The standardized regression weights for all variables are significant at the 0.05 level (Table 3 ). This finding indicates that all hypotheses are proved, and there is a positive, linear correlation between all components of DM and HRM. In other words, if the DM components are enhanced, HRM practices will be positively influenced.

\section{Table 3. Regression Analysis}

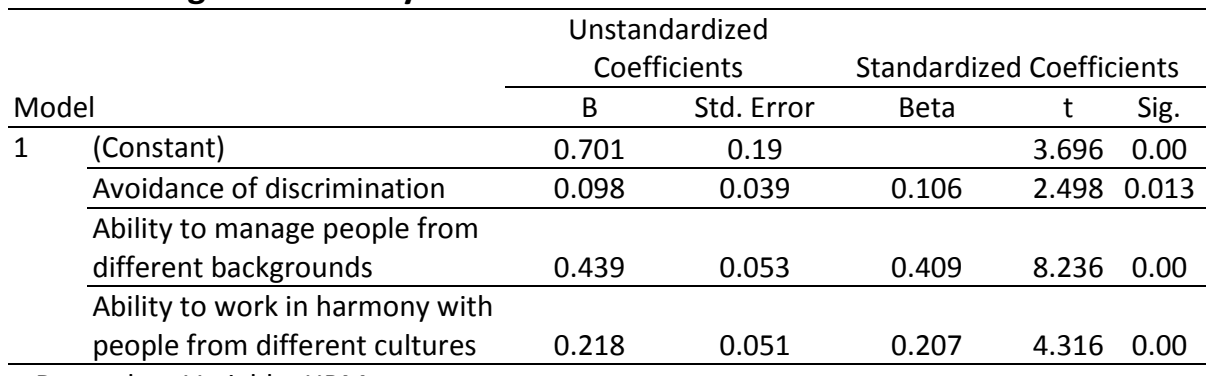

a Dependent Variable: HRM

Table 4. Correlation Analysis

\begin{tabular}{|c|c|c|c|c|c|}
\hline & & HRM & $\begin{array}{c}\text { Avoidance } \\
\text { of } \\
\text { discrimina } \\
\text { tion } \\
\end{array}$ & $\begin{array}{c}\text { Ability to } \\
\text { work manage } \\
\text { people from } \\
\text { different } \\
\text { backgrounds }\end{array}$ & $\begin{array}{l}\text { Ability to } \\
\text { work in } \\
\text { harmony with } \\
\text { people from } \\
\text { different } \\
\text { cultures }\end{array}$ \\
\hline \multirow{3}{*}{ HRM } & $\begin{array}{l}\text { Pearson } \\
\text { Correlation }\end{array}$ & 1 & $.354 * *$ & ,579** &, $494 * *$ \\
\hline & Sig. (2-tailed) & & 0 & 0 & 0 \\
\hline & $\mathrm{N}$ & 437 & 437 & 437 & 437 \\
\hline \multirow{3}{*}{$\begin{array}{l}\text { Avoidance of } \\
\text { discrimination }\end{array}$} & $\begin{array}{l}\text { Pearson } \\
\text { Correlation }\end{array}$ &, $354 * *$ & 1 &, $440 * *$ &, $373 * *$ \\
\hline & Sig. (2-tailed) & 0 & & 0 & 0 \\
\hline & $\mathrm{N}$ & 437 & 442 & 441 & 442 \\
\hline \multirow{3}{*}{$\begin{array}{l}\text { Ability to work } \\
\text { manage people } \\
\text { from different } \\
\text { backgrounds }\end{array}$} & $\begin{array}{l}\text { Pearson } \\
\text { Correlation }\end{array}$ &, $579 * *$ &, $440 * *$ & 1 & ,603** \\
\hline & Sig. (2-tailed) & 0 & 0 & & 0 \\
\hline & $\mathrm{N}$ & 437 & 441 & 441 & 441 \\
\hline \multirow{3}{*}{$\begin{array}{l}\text { Ability to work in } \\
\text { harmony with } \\
\text { people from } \\
\text { different cultures }\end{array}$} & $\begin{array}{l}\text { Pearson } \\
\text { Correlation }\end{array}$ &, $494 * *$ &, $373 * *$ &, $603 * *$ & 1 \\
\hline & Sig. (2-tailed) & 0 & 0 & 0 & \\
\hline & $\mathrm{N}$ & 437 & 442 & 441 & 442 \\
\hline
\end{tabular}

${ }^{* *}$ Correlation is significant at the 0,01 level (2-Tailed)

According to the research findings, among the DM components the "ability to manage people from different backgrounds" component seems to have the most significant effect (0.4) on HRM practices. The outcomes of workforce diversity have 
been analyzed from different perspectives. For example, Kossek et al. analyzed the level of diversity and group climate, and their research finding partially supported the idea that greater structural demographic shift would positively relate to a more favorable climate for diversity (Kossek, et al., 2003). Benchop's research findings (2001) explored that organization's strategy for managing diversity positively influences HRM practices. There are also other studies that disclose the relationship between the ability of an organization to manage diversified work force and HRM outcomes in organization level (Nyambegera, 2002) or functional level (Kossek, et al., 2006).

"Ability to work in harmony with people from different cultures" appears as the second important component of DM that affects HRM (0.2). In literature, both positive and negative outcomes of working with people from different cultures have been mentioned. For example, Vodosek (2007), Ely and Thomas (2001), and Kochan, et al. (2003) disclosed both positive and negative outcomes of working with diversified workforce. Therefore, the ability to work in harmony is considered as an important aspect of cultural diversity (Sutton \& Pierce, 2003). Comparatively less empirical evidences can be found in literature regarding to direct effects of cultural diversity and HRM in organizational level (Laurent, 1986; Benschop, 2001). However, there are more research findings revealing the so-called relationship in the team level (Thomas, 1999; Sutton \& Pierce, 2003; Staples \& Zhao, 2006).

"Avoidance of discrimination" is also positively correlated with HRM but has the least effect compared to other DM components. There is a wide range of literature regarding various types of discrimination in HRM literature. In this respect, legal outcomes of discrimination (Bennington \& Roberts-Calvert, 1997), importance of avoidance of discrimination (Dickens, 1998) and positive discrimination (Noon, 2010) attracted the attention of the researchers in the last few decades. There is almost a consensus that avoiding discrimination is an important responsibility of HRM and is positively related with HRM outcomes (Dickens, 1998; Jenkins, 2008; Harel, et al., 2003).

\section{Implications}

\subsection{Theoretical implications}

The findings of this study have wide support in literature. Using factor analysis approach, Meena and Vanka (2017) argue for seven diversity-oriented human resource management practices (i.e. fairness-oriented selection practices, fairnessoriented performance evaluation practices, fairness-oriented compensation, practices, training-oriented practices, team-oriented practices, control-oriented practices and Identity-free practices). Previous studies also suggest that DM results in HRM practices promote fairness and training (Roberge, et al., 2011). Furthermore, High HRM investments in pay, benefit, training, and communication strengthen the influence of gender diversity on workforce productivity (Roh and Kim, 2016). 
Despite the acknowledgement of DM positive effect on HRM, inequality and discrimination is still widespread in organizations worldwide. In this sense, HRM practices are predominantly dealing with maintaining compliance with equal employment opportunity and affirmative action legislation (Shen, et al., 2009).

However, there is also an important perspective that should be taken into consideration when assessing DM in GCC work environments. As a matter of fact, research informs that legislations in some countries may impose more constraints on employer's willingness to promote diversity (Klarsfeld, et al., 2016). Since this research uses data gathered from Kuwaiti organizations, the power of DM influence on HRM can be underestimated given the role of local regulatory system that imposes varying quota-based policies depending on the sector of activity.

\subsection{Practical implications}

The analysis of data collected from companies in service sector in Kuwait has revealed the positive implication of diversity management on human resources. This implies that the Kuwaiti executives may attempt to create a supportive working business environment. These executives should concentrate on those components of diversity management that have the most significant effect on HRM practices in service sector in Kuwait, viz., "ability to manage people from different backgrounds", "ability to work in harmony with people from different cultures" and finally "avoidance of discrimination". As the workplace diversity increases HR responsibility, a professional, periodical, systematic and structured data collection and analysis should be conducted to closely monitor and communicate the progress to the management in this regard.

\section{Conclusions}

This paper uses strategic HRM perspective to study diversity management in Kuwait, characterized by unique labor legislation and manpower composition. The outcomes of this study confirm that HRM functions are regarded as a vehicle for diversity management in Kuwaiti organizations. Taking into consideration the results of this study, diversity management is addressed more or less effectively than a simple slogan.

This paper conveys substantial contribution to diversity management studies in organizations. On one hand, the findings expose HRM as a tremendous means for the application of diversity management in Kuwaiti organizations. HRM functions, accordingly, can be regarded as an imminent tool for organizations in the pursuit of effective implementation of diversity management principles. On the other hand, and contrary to established beliefs about the existence of untapped foreign manpower in GCC countries, the results unveil the remarkable eagerness of Kuwaiti organizations to harness diversity merits. These results, however, are quite reasonable if the particularity of local context is taken into account. As a matter of fact, Kuwait economy is dependent to a large proportion on foreign workforce. Key 
positions - particularly in the private sector - are evenly held by either local or foreign employees. The ambitious Kuwait 2035 vision would certainly increase manpower needs and trigger extensive employment in international job market.

As limitation of this study, social desirability could have biased the answers collected from the participants in the survey. Our respondents are undoubtedly wary of providing answers that do not violate widely agreed upon ethical principles. The perceptional nature of data used in this research represents another limitation to potential generalization of the results.

\section{Suggestions for future research}

This study identified diversity management variables and its influence on HRM practices in the service sector in Kuwait. However, this raises a number of questions which can be answered through more research.

For instance, the causal relationship between diversity management and HRM needs further investigation in order to discriminate the distinctive effect of diversity management on each of HRM functions. For instance, we would expect recruitment to be the most exploited platform to showcase firm's commitment towards promoting diversity management. This research avenue would contribute in examining most commonplace diversity management practices in Kuwaiti organizations which could provide useful insights for local firms to increase organizational performance and employee productivity.

In addition, the results could be segregated according to firm-based factors, such as ownership form, size, global orientation, type of activity, etc. This would certainly reveal interesting facts about the status of diversity management in Kuwait. Future studies could be interested in how diversity management, as part of strategic HRM has been applied in Kuwaiti organizations, across different ownership forms Public versus Private; domestic versus multinational firms.

Therefore, this study can be conducted on a larger scale using structural equation modeling to account for the intertwined effects of independent diversity management variables.

In addition, it would be interesting to examine the effect of the relationship between DM and HRM practices on employees' attitudes (i.e., job satisfaction, organizational commitment, organizational citizenship behaviors, etc...), since there is a lack of such studies in Kuwait.

\section{References}

Ali, A. J., and Al-Kazemi, A. (2006). Human Resouce Management in Kuwait. In: P. S. Budhwar and K. Mellahi, eds. Managing Human Resources in the Middle-East (pp. 79-95). Abingdon: Routledge. 
Ali, M., Metz, I., \& Kulik, C. T. (2015). The impact of work-family programs on the relationship between gender diversity and performance. Human Resource Management, 54(4), 553-576. https://doi.org/10.1002/hrm.21631

Ardakani, M. S., Abzari, M., Shaemi, A., \& Fathi, S. (2016). Diversity Management and human resources productivity: Mediating effects of perceived organizational attractiveness, organizational justice and social identity in Isfahan's steel industry. Iranian Journal of Management Studies, 9(2), 407-432.

Ashikali, T., \& Groeneveld, S. (2015). Diversity management for all? An empirical analysis of diversity management outcomes across groups. Personnel Review, 44(5), 757-780. https://doi.org/10.1108/PR-10-2014-0216

Baird, L., \& Meshoulam, I. (1998). Managing two fits of strategic human resource management. Academy of Management Review, 13(1), 116-128. https://doi.org/10.5465/AMR.1988.4306802

Bendl, R., Fleischmann, A. \& Walenta, C. (2008). Diversity management discourse meets queer theory. Gender in Management: An International Journal, 23(6), 382-394. https://doi.org/10.1108/17542410810897517

Bennington, L. \& Roberts-Calvert, B. (1997). Anti-discrimination legislation and HRM practice. Caulfield East, Vic.: Dept. of Management, Faculty of Business and Economics, Monash University.

Benschop, Y. (2001). Pride, prejudice and performance: Relations between HRM, diversity and performance. International Journal of Human Resource Management, 12(7), 1166-1181. https://doi.org/10.1080/09585190110068377

Celebioglu, F. (2017). Women Employment in terms of Gender Inequality across the Provinces of Turkey. Eurasian Journal of Business and Economics, 10(19), 61-80. https://doi.org/10.17015/ejbe.2017.019.04

Cooke, F. \& Saini, D. (2010). Diversity management in India: A study of organizations in different ownership forms and industrial sectors. Human Resource Management, 49(3), 477500. https://doi.org/10.1002/hrm.20360

Dickens, L. (1998). What HRM means for gender equality. Human Resource Management Journal, 8(1), 23-40. https://doi.org/10.1111/j.1748-8583.1998.tb00157.x

Donnelly, R. (2015). Tensions and Challenges in the Management of Diversity and Inclusion in IT Services Multinationals in India. Human Resource Management, 54(2), pp. 199-215. https://doi.org/10.1002/hrm.21654

Ely, R. J. \& Thomas, D. A. (2001). Cultural diversity at work: The effects of diversity perspectives on work group processes and outcomes. Administrative Science Quarterly, 46(2), 229-273. https://doi.org/10.2307/2667087

Forstenlechner, I., Lettice, F., \& Özbilgin, M. (2012). Questioning quotas: applying a relational framework for diversity management practices in the United Arab Emirates. Human Resource Management Journal, 22(3), 299 - 315. https://doi.org/10.1111/i.17488583.2011.00174.x

Friday, E. \& Friday, S. S. (2003). Managing diversity using a strategic planned change approach. Journal of Management Development, 22(10), 863-880. https://doi.org/10.1108/02621710310505467 
Goby, V. P., Nickerson, C., \& David, E. (2015). Interpersonal communication and diversity climate: Promoting workforce localization in the UAE. International Journal of Organizational Analysis, 23(3), 364-377. https://doi.org/10.1108/IJOA-09-2014-0796

Harel, G., Tzafrir, S. \& Baruch, Y. (2003). Achieving organizational effectiveness through promotion of women into managerial positions: HRM practice focus, 14(2), 247-263.

Hung, D. K. M., Ansari, M. A. \& Aafaqi, R. (2004). Fairness of human resource management practices, leader-member exchange and organizational commitment. Asian Academy of Management Journal, 9(1), 99-120.

Iles, P., Almhedie, A., \& Baruch, Y. (2012). Managing HR in the Middle East: Challenges in the public sector. Public Personnel Management, 41(3), 465-492. https://doi.org/10.1177/009102601204100305

Jamali, D., Abdallah, H., \& Hmaidan, S. (2010). The challenge of moving beyond rhetoric: paradoxes of diversity management in the Middle East. Equality, Diversity and Inclusion: An International Journal, 29(2), 167-185. https://doi.org/10.1108/02610151011024484

Jenkins, A. K. (2008). Age discrimination in hotel workplaces: HRM practices and their effects on the employment of "older" workers. Glasgow, University of Strathclyde.

Jie, S., D'Netto, B., \& Jiong, T. (2010). Effects of human resource diversity management on organizational citizen behaviour in the Chinese context. International Journal of Human Resource Management, 21(12), 2156-2172. https://doi.org/10.1080/09585192.2010.509622

Kandola, R. S., \& Fullerton, J. (1998). Diversity in Action: Managing the Mosaic. s.I.:CIPD Publishing.

Klarsfeld, A., Ng, E. S., Booysen, L., Castro Christiansen, L., \& Kuvaas, B. (2016). Comparative equality and diversity: Main findings and research gaps. Cross Cultural and Strategic Management, 23(3), 394-412. https://doi.org/10.1108/CCSM-03-2016-0083

Kochan, T., Bezrukova, K., Ely, R., Jackson, S., Joshi, A., Jehn, K., Leonard, J., Levine, D., \& Thomas, D. (2003). The effects of diversity on business performance: Report of the diversity research network. Human Resource Management, 42(1), 3-21. https://doi.org/10.1002/hrm.10061

Konrad, A., Yang, Y., \& Maurer, C. (2016). Antecedents and outcomes of diversity and equality management systems: An integrated institutional agency and strategic human resource management approach. Human Resource Management, 55(1), 83-107. https://doi.org/10.1002/hrm.21713

Kossek, E. E., Lobel, S. A., \& Brown, J. (2006). Human resource strategies to manage workforce diversity. In: A. M. Konrad, P. Prasad and J. K. Pringle, eds. Handbook of Workplace Diversity (pp. 53-74). London: Sage. https://doi.org/10.4135/9781848608092.n3

Kossek, E. E., Markel, K. S., \& McHugh, P. P. (2003). Increasing diversity as an HRM change strategy. Journal of Organizational Change Management, 16(3), 328-352. https://doi.org/10.1108/09534810310475550

Kuwait Central Statistical Bureau. (2015, December). Annual Statistical Abstract: Central Statistical Bureau. Retrieved February 15, 2017, from https://www.csb.gov.kw/Socan Statistic EN.aspx?ID=18

Lamba, S., \& Choudhary, N. (2013). Impact of HRM practices on organizational commitment of employees. International Journal of Advancements in Research and Technology, 2(4), 407423. 
Laurent, A. (1986). The cross-cultural puzzle of international human resource management. Human Resource Management, 25(1), 91-102. https://doi.org/10.1002/hrm.3930250107

Louvrier, J. (2014). Diversity Management: At the center of HRM and Leadership. Liiketaloudellinen Aikakauskirja, 4, 323-329.

Marchington, M., \& Grugulis, I. (2000). 'Best practice' human resource management: perfect opportunity or dangerous illusion? International. Journal of Human Resource Management, 11(6), 1104-1124. https://doi.org/10.1080/09585190050177184

McMahan, G. C., Bell, M. P., \& Virick, M. (1998). Strategic human resource management: Employee involvement, diversity, and international issues. Human Resource Management Review, 8(3), 193-214. https://doi.org/10.1016/S1053-4822(98)90002-X

Meena, K., \& Vanka, S. (2017). Developing an empirical typology of diversity-oriented human resource management practices. Journal of Management Development, 36(7), 915929. https://doi.org/10.1108/JMD-02-2016-0031.

Naz, F., Aftab, J., \& Awais, M. (2016). Impact of human resource management practices (HRM) on performance of SMEs in Multan, Pakistan. International Journal of Management, Accounting and Economics, 3(11), 699-708.

Noon, M. (2010). The shackled runner: Time to rethink positive discrimination? Work, Employment and Society, 24(4), 728-739. https://doi.org/10.1177/0950017010380648

Nyambegera, S. M. (2002). Ethnicity and human resource management practice in subSaharan Africa: the relevance of the managing diversity discourse. International Journal of Human Resource 1077-1090. https://doi.org/10.1080/09585190210131302

Pfeffer, J. (1998). Seven practices of successful organizations. California Management Review, 40(2), 96-124. https://doi.org/10.2307/41165935

Ravazzani, S. (2016). Understanding approaches to managing diversity in the workplace: an empirical investigation in Italy. Equality, Diversity and Inclusion: An International Journal, 35(2), 154-168. https://doi.org/10.1108/EDI-08-2014-0062

Richard, O. C., Roh, H., \& Pieper, J. R. (2013). The link between diversity and equality management practice bundles and racial diversity in the managerial ranks: Does firm size matter? Human Resource Management, 52(2), 215-242. https://doi.org/10.1002/hrm.21528

Roberge, M.É., Lewicki, R.J., Hietapelto, A., \& Abdyldaeva, A. (2011). From theory to practice: Recommending supportive diversity practices. Journal of Diversity Management, 6(2), 1-20.

Roh, H., \& Kim, E. (2016). The business case for gender diversity: Examining the role of human resource management investments. Human Resource Management, 55(3), 519-534. https://doi.org/10.1002/hrm.21736

Shen, J., Chanda, A, D'Netto, B., \& Monga, M. (2009). Managing diversity through human resource management: an international perspective and conceptual framework. The International Journal of Human Resource Management, 20 (2), 235-251 https://doi.org/10.1080/09585190802670516

Staples, D. S., \& Zhao, L. (2006). The effects of cultural diversity in virtual teams versus faceto-face teams. Group Decision and Negotiation, 15(4), 389-406. https://doi.org/10.1007/s10726-006-9042-x 
Oualid ABIDI, Halil ZAIM, Dina YOUSSEF, Houshang HABIBNIYA \& Alper BARAN

Sutton, J. L., \& Pierce, L. G. (2003). A framework for understanding cultural diversity in cognition and teamwork. Washington DC, the 8th International Command and Control Research and Technology Symposium.

Thomas, D. C. (1999). Cultural diversity and work group effectiveness an experimental study. $\begin{array}{llll}\text { Journal of Cross-cultural Psychology, 242-263. } & \text { 30(2), }\end{array}$ https://doi.org/10.1177/0022022199030002006

Vodosek, M. (2007). Intragroup conflict as a mediator between cultural diversity and work group outcomes. International Journal of Conflict Management, 18(4), 345-375. https://doi.org/10.1108/10444060710833469

Yaghi, A., \& Yaghi, I. (2013). Human resource diversity in the United Arab Emirates: empirical study. Education, Business and Society: Contemporary Middle Eastern Issues, 6(1), 15-30. https://doi.org/10.1108/17537981311314682

Zaim, H. (2016). Analysing the effects of knowledge management processes on human resource management practices: A case study on an oil company in the Gulf region. Middle East Journal of Management, 3(3), 230-243. https://doi.org/10.1504/MEJM.2016.079749 